\title{
Pathophysiology, risk factors, and screening methods for prediabetes in women with polycystic ovary syndrome
}

This article was published in the following Dove Press journal:

International Journal of Women's Health

10 August 2016

Number of times this article has been viewed

\author{
Evgenia Gourgari' \\ Elias Spanakis ${ }^{2}$ \\ Adrian Sandra Dobs ${ }^{3}$ \\ 'Division of Pediatric Endocrinology, \\ Georgetown University School of \\ Medicine, Washington, DC, ${ }^{2}$ Division \\ of Endocrinology, University of \\ Maryland School of Medicine, \\ ${ }^{3}$ Department of Endocrinology, \\ Johns Hopkins University School \\ of Medicine, Baltimore, MD, USA
}

\begin{abstract}
Polycystic ovary syndrome (PCOS) is a syndrome associated with insulin resistance (IR), obesity, infertility, and increased cardiometabolic risk. This is a descriptive review of several mechanisms that can explain the IR among women with PCOS, other risk factors for the development of diabetes, and the screening methods used for the detection of glucose intolerance in women with PCOS. Few mechanisms can explain IR in women with PCOS such as obesity, insulin receptor signaling defects, and inhibition of insulin-mediated glucose uptake in adipocytes. Women with PCOS have additional risk factors for the development of glucose intolerance such as family history of diabetes, use of oral contraceptives, anovulation, and age. The Androgen Society in 2007 and the Endocrine Society in 2013 recommended using oral glucose tolerance test as a screening tool for abnormal glucose tolerance in all women with PCOS. The approach to detection of glucose intolerance among women with PCOS varies among health care providers. Large prospective studies are still needed for the development of guidelines with strong evidence. When assessing risk of future diabetes in women with PCOS, it is important to take into account the method used for screening as well as other risk factors that these women might have.
\end{abstract}

Keywords: IR, OGTT, obesity, hyperandrogenism, anovulation, BMI, insulin resistance, PCOS

\section{Introduction}

Polycystic ovary syndrome (PCOS) is a syndrome associated with insulin resistance (IR), obesity, infertility, and increased cardiometabolic risk. The diagnosis of PCOS based on the National Institutes of Health 1990 criteria includes clinical and/or biochemical evidence of hyperandrogenism and chronic anovulation and exclusion of other known disorders. According to the Rotterdam 2003 criteria, PCOS is diagnosed based on the presence of two of the following three features: oligo- or anovulation, clinical and/or biochemical signs of hyperandrogenism, or polycystic ovaries. Finally, the Androgen Excess Society 2006 criteria require the presence of hyperandrogenism (biochemical or clinical) with either oligoanovulation or polycystic ovaries. ${ }^{1}$ The Endocrine Society 2013 guidelines suggested using the Rotterdam criteria for diagnosing PCOS. ${ }^{1}$

There is a lack of large prospective studies investigating the natural history of glucose intolerance among women with PCOS. The Androgen Excess Society in 2007 and the Endocrine Society in 2013 recommended using oral glucose tolerance test (OGTT) as a screening method. ${ }^{1}$ Few members of the Androgen Excess Society had the opinion that OGTT should only be performed in women with PCOS and a body mass index $(\mathrm{BMI})>30 \mathrm{~kg} / \mathrm{m}^{2}$ or in lean women with other risk factors. ${ }^{2}$ Taking into
Correspondence: Evgenia Gourgari Division of Pediatric Endocrinology, Georgetown University Hospital, 4200 Wisconsin Avenue, North West, 4th Floor, Washington, DC 20016, USA

Tel +l 2022433560

Fax +l 8776805507

Email evgenia.gourgari@gunet. georgetown.edu
International Journal of Women's Health 2016:8 38I-387

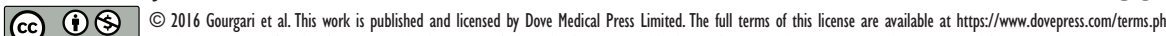

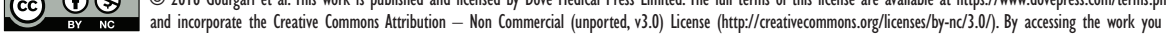
hereby accept the Terms. Non-commercial uses of the work are permitted without any further permisision from Dove Medical Press Limited, provided the work is properly atributed. For permision for commercial use of this work, please see paragraphs 4.2 and 5 of our Terms (https://www.dovepress. com/terms.php). 
consideration the cost and time needed to perform a 2-hour OGTT, the approach to detection of glucose intolerance among women with PCOS varies among health care providers. In this review, we summarize several mechanisms that can explain the IR which leads to glucose intolerance among women with PCOS, other risk factors for the development of diabetes, and the screening methods used for the detection of glucose intolerance in women with PCOS. Given the strong correlation of obesity and IR, we also examined separately the studies on lean women with PCOS. In this descriptive review, we used computerized search processes to identify English language articles related to PCOS and IR in the literature. The search strategy used to identify articles included combinations of the following terms: PCOS, IR, screening, lean PCOS, HbAlc, and OGTT.

\section{Pathophysiology and risk factor for prediabetes in women with PCOS}

There are a few different pathophysiologic mechanisms and risk factors for prediabetes in women with PCOS. A brief overview of these risk factors is given as follows.

Obesity is present in $\sim 50 \%-80 \%$ of women with PCOS, but this relationship also depends on environmental factors. ${ }^{3}$ Lower rates of obesity in women with PCOS have been reported in different countries around the world. ${ }^{4}$ In populations where severe obesity is less prevalent such as the Asians and some Europeans, PCOS is still present at almost the same frequency. ${ }^{5}$ One could argue that there are no more obese PCOS women than obese non-PCOS women in a certain community. ${ }^{6} \mathrm{With}$ increasing age, there is also worsening of BMI, waist-to-hip ratio, and IR among women with PCOS..$^{7-10}$ The majority of obese women though are actually fertile and do not have reproductive abnormalities. ${ }^{5}$ Furthermore, obesity increases over time the rate of conversion from normal to abnormal glucose tolerance and diabetes. Norman et al studied prospectively a group of 67 women with PCOS by performing a $75 \mathrm{~g}$ OGTT at baseline and after an average time of 6.2 years. ${ }^{11}$ BMI was considered an independent risk factor for the development of diabetes in women with PCOS. In their study, PCOS women with a BMI $>30 \mathrm{~kg} / \mathrm{m}^{2}$ were ten times more likely to develop impaired glucose tolerance (IGT) or diabetes when compared to PCOS women with a BMI $<25 \mathrm{~kg} / \mathrm{m}^{2}$, and women with a BMI of $25-30 \mathrm{~kg} / \mathrm{m}^{2}$ were seven times more likely to have deteriorated glucose profile with increasing age. The conversion rate from normal to abnormal glucose tolerance is worse in obese women with PCOS when compared to the general population. Legro et al found a conversion rate from normoglycemia to abnormal glucose of $16 \%$ per year in obese women with PCOS when compared to the expected conversion rate of $1 \%-5 \%$ per year in the general obese population, ${ }^{12}$ but the conversion rate from IGT to diabetes was not increased ( $2 \%$ per year). In Norman et al's study, although the conversion rate to diabetes was similar (2.6\% per year), the risk of diabetes was significantly higher among women who had baseline IGT (8.6\% per year). ${ }^{11}$ In Legro et al's study, there was an insufficient number of lean women with PCOS to assess the effect of BMI on conversion rates. Another group studied women with PCOS for 8 years and found that women who eventually developed type 2 diabetes had higher baseline BMI. ${ }^{13}$ These studies highlight the synergic effect of obesity in deteriorating the glucose tolerance in PCOS women at baseline and over time. ${ }^{14,15}$

Studies have evaluated the subcutaneous and visceral fat distribution in obese PCOS women using dual-energy $\mathrm{X}$-ray absorptiometry and magnetic resonance imaging techniques with conflicting results. Women with PCOS have an increased waist-to-hip ratio when compared to BMI-matched controls. Some studies have shown that women with PCOS have higher central adiposity and higher upper-to-lower body fat distribution measured by dual X-ray absorptiometry, magnetic resonance imaging, or ultrasound, even if they have the same total fat and trunk fat as BMI-matched controls. ${ }^{16-18}$ Central adiposity is a risk factor for prediabetes in women with PCOS.

Another risk factor for prediabetes among women with PCOS is their age. In a study of 112 women with PCOS and 86 controls, age, along with obesity, was one of the major determinants of IR and diabetes. ${ }^{9}$ A large retrospective study of 2,301 women with PCOS also found significant correlation between age and risk of type 2 diabetes. ${ }^{10}$ The same adverse effect of age on IR was found in a prospective study of 254 women with PCOS. ${ }^{8}$ In a study on a Chinese population of 356 PCOS women and 974 infertile control women, age was also found to be a significant predictor of glucose intolerance during an OGTT. ${ }^{19}$ In a study on a Korean population, the prevalence of glucose intolerance (calculated by OGTT) was $6.3 \%$ in women aged $16-19$ years, $11.2 \%$ (14 of 125$)$ in women with PCOS aged 20-29 years, and 34\% (18 of 53) in women with PCOS aged 30-39 years. ${ }^{20}$ These studies indicate that older age is a risk factor for IR.

Also, the use of oral contraceptives (OCs), a treatment option commonly used by women with PCOS, has been linked to worsening of IR in some studies. ${ }^{21}$ Various OC pills can have different effects on the glucose metabolism. The mechanism by which OCs deteriorate IR is unclear. 
One proposed theory is that OCs decrease the insulin receptor binding. ${ }^{22}$ Another theory is that use of OCs might impair beta-cell function, as some small studies have shown that women taking OCs have lower disposition index during the frequently sampled intravenous glucose tolerance test. ${ }^{23}$

A large older study followed 1,060 women who were taking various types of OCs for at least 3 months and 418 control women. Depending on the dose and type of progestin, women who were taking OCs were found to have 43\%-61\% higher plasma glucose levels in the OGTT when compared to controls. The worst effect was seen with levonorgestrel combination pill, and the least effect with low-dose norethindrone pill. ${ }^{24}$ These OCs contained 30-40 $\mu \mathrm{g}$ of ethinyl estradiol (EE), which is much higher than the doses used today.

Similar studies have been done in women with PCOS. The effect of metformin versus OC therapy on IR was evaluated in a study on 100 overweight women with PCOS. While metformin reduced IR by $34 \%$, the high-dose OC (35 $\mu \mathrm{g}$ EE/2 mg cyproterone acetate) increased IR by $25 \%$. The low-dose OC $(20 \mu \mathrm{g}$ EE/100 $\mu \mathrm{g}$ levonorgestrel plus aldactone) had a neutral effect. The BMI was stable during treatment. ${ }^{25}$ Another group in Finland randomized 32 obese (BMI $>27 \mathrm{~kg} / \mathrm{m}^{2}$ ) women with PCOS to metformin or to EE $35 \mathrm{mg}$ /cyproterone acetate $2 \mathrm{mg}$ OC pill. This group observed worsening of glucose tolerance after 6 months. ${ }^{26}$ On the contrary, when the same regimen of OC was used in lean $\left(\mathrm{BMI}<25 \mathrm{~kg} / \mathrm{m}^{2}\right)$ women with PCOS, no adverse effect on glucose tolerance was seen in the OGTT, which highlights a possible synergic effect of BMI and certain OCs in deteriorating the glucose tolerance. ${ }^{27}$ In a more recent study that compared the metabolic effects of $\mathrm{OC}$ and exercise among 150 women with PCOS, no difference was seen in fasting glucose (FG), insulin, homeostasis model assessment, and area under the curve from an OGTT after 6 months of treatment with $3 \mathrm{mg}$ drospirerone and $30 \mu \mathrm{g}$ of EE. ${ }^{28}$ These studies indicate that certain OCs can deteriorate glucose tolerance in women with PCOS. ${ }^{29}$ It is therefore recommended that physicians consider other risk factors for prediabetes when prescribing OCs. ${ }^{30}$

Race is also another determinant of future risk of diabetes. African-American, Caribbean-Hispanic, and south Asian women with PCOS are at a higher risk of diabetes. ${ }^{10,31}$ The prevalence of IGT among women with PCOS in the Mediterranean area, such as Spain and Italy, has been found to be lower when compared to studies done in the US. It is possible that racial, dietary, or lifestyle differences can explain this discrepancy. ${ }^{9,32}$ These studies highlight the importance of race as a risk factor for IR in women with PCOS.
Family history of diabetes has also been found in multiple studies to significantly increase the risk of development of glucose intolerance among women with PCOS. ${ }^{9,31-33}$ In one of these studies, data from 408 women with PCOS were analyzed. Family history of diabetes was found in $44 \%$ of PCOS women with diabetes and $39 \%$ of women with IGT, but only $21 \%$ of PCOS women with normal glucose tolerance had a family history of diabetes. ${ }^{31}$ These studies indicate that the presence of family history of diabetes is a risk factor for prediabetes in women with PCOS.

Women with PCOS who have highly irregular menstrual cycles are also at a higher risk of diabetes. Data from the Nurses Health Study II, in which 101,073 women were enrolled and followed for 12 years, showed that women with highly irregular menstrual cycles have an increased risk of developing diabetes. ${ }^{34}$ Another large study followed a cohort of 23,571 women for 10 years and reached the same conclusion: irregular menstrual cycles are related to future risk of type 2 diabetes. ${ }^{35}$ Recently, in a study among 494 women with PCOS, it was shown that patients with menstrual cycles $>35$ days had higher mean homeostasis model assessment - IR levels than controls, in contrast to women with PCOS and regular cycles who were no different than controls. ${ }^{36}$ These studies illustrate the association of highly irregular menses with the risk of prediabetes in women with PCOS.

In summary, obesity and central adiposity, family history of diabetes, irregular menses, use of certain OCs, older age, and African-American, Caribbean-Hispanic, or south Asian race are risk factors for prediabetes in women with PCOS.

\section{Molecular mechanisms of IR among women with PCOS}

There are several molecular mechanisms that can explain IR among women with PCOS. Beta-cell dysfunction has been investigated as a possible mechanism for IR among women with PCOS. ${ }^{37}$ Both obese and nonobese PCOS women have beta-cell dysfunction, although this is not associated with glucose intolerance in the majority of women. ${ }^{38}$ The impaired beta-cell function can start early in life. Obese adolescents with PCOS have decreased first-phase insulin secretion, decreased glucose disposition index, and increased hepatic glucose production. ${ }^{39}$

The insulin signal pathway can be impaired by tyrosine phosphatases that dephosphorylate the insulin receptor. Moreover, serine phosphorylation of the insulin receptor and insulin receptor substrates can also lead to IR. ${ }^{3}$ Another mechanism for IR is failure of insulin to activate glycogen 
synthase (GS). GS is activated by decreased phosphorylation at regulatory sites. The IR in muscle tissue in PCOS women could be partially explained by impaired insulin activation of GS, including absent dephosphorylation. ${ }^{40}$

Moreover, microscopically, the fat tissue in women with PCOS is different. The adipocytes in both obese and lean women with PCOS are larger in size and have increased CD11c expression, which has been linked to IR through increased release of inflammatory cytokines. ${ }^{41,42}$ In addition, the fat tissue is not just a storage tissue, but it secretes hormones, such as adiponectin and leptin. PCOS women have been found to have low adiponectin and high leptin, irrespective of BMI. ${ }^{42,43}$ These alterations in the function of adipose tissue can also partially explain the decreased insulin sensitivity in women with PCOS, given the insulinsensitizing properties of adiponectin.

Finally, there is emerging evidence about the association of inflammation with IR in women with PCOS. Elevated inflammatory markers have been linked to IR in women with PCOS, such as CRP, interleukin-18, and TNF- $\alpha .^{44,45}$ Furthermore, adhesion molecules that are markers of endothelial dysfunction, such as soluble vascular cell adhesion molecule-1, soluble intercellular adhesion molecule-1, endothelin 1, and sE-selectin, have also been linked to IR in women with PCOS. ${ }^{44,46}$ Women with PCOS also exhibit abnormalities in their lipoprotein profile, such as low highdensity lipoprotein and high low-density lipoprotein, which have been associated with IR and obesity. ${ }^{47-49}$

\section{Screening methods for glucose intolerance in PCOS}

The American Diabetes Association recommends testing for diabetes or prediabetes using the glycated hemoglobin (HbA1c), fasting plasma glucose, or $75 \mathrm{~g}$ 2-hour OGTT. ${ }^{50}$ The Rotterdam PCOS Consensus Workshop Group in 2003 recommended using OGTT for women with PCOS with a $\mathrm{BMI}>27 \mathrm{~kg} / \mathrm{m}^{2}{ }^{2}$ The Androgen Society recommended in 2007 using OGTT as a screening tool for abnormal glucose tolerance in all women with PCOS. A few members suggested performing an OGTT only in patients with a $\mathrm{BMI} \geq 30 \mathrm{~kg} / \mathrm{m}^{2}$ or in lean patients with additional risk factors. ${ }^{51}$ The Endocrine Society 2013 guidelines did not alter this recommendation. ${ }^{1}$ Several studies have shown that FG is not a sensitive measurement for diagnosing IGT and diabetes in women with PCOS.

The prevalence of IGT has been studied in women with PCOS. Glucose intolerance measured by 2-hour glucose after an OGTT was abnormal in $45 \%$ of 122 women with PCOS, of which $10 \%$ were diagnosed with diabetes. When using FG, abnormal result was found only in $15 \%$ of women, of which $6 \%$ were diagnosed with diabetes. This was clearly an evidence of poor sensitivity of FG to detect IGT or diabetes in women with PCOS. ${ }^{33}$ Based on the 2-hour glucose value, $31 \%$ of women had IGT and $7.5 \%$ had diabetes. However, based on the FG value alone, only $3.2 \%$ of these women would have been diagnosed with diabetes. ${ }^{8}$ When data from these two studies were merged, the FG was found to have a poor correlation with the 2-hour glucose in women with IGT $(r=0.115) .{ }^{31}$ In another study, 111 women with PCOS were screened for glucose abnormalities. Diabetes and IGT were diagnosed by OGTT in $4 \%$ and $20 \%$ of subjects, respectively. Screening of 111 PCOS women by using fasting plasma glucose failed to identify $41 \%$ of women with impaired glucose and $20 \%$ of diabetic subjects. ${ }^{52}$ In a study done in Prague, $12.3 \%$ of 244 women with PCOS had abnormal FG, and $9.4 \%$ were found to have impaired glucose and $1.6 \%$ were found to have diabetes by OGTT. In this study, only seven of the 30 women identified by FG were found to have abnormal glucose tolerance by OGTT. ${ }^{53}$ In Brazil, a study done in 85 young women with PCOS identified $27.0 \%$ with IGT and $4.8 \%$ with diabetes when the 2-hour glucose value from OGTT was used as a diagnostic criterion; however, only $15.3 \%$ were diagnosed with IGT and $1.2 \%$ with diabetes when the FG was used. ${ }^{54}$ A small study in adolescents with PCOS showed again failure of FG to predict abnormal glucose tolerance ( $7 \%$ versus $33 \%$ in this study). ${ }^{55}$ The same was shown in a study done in 194 Korean women with PCOS. FG failed to detect $94 \%$ of those with abnormal glucose tolerance detected by OGTT. ${ }^{20}$ Receiver operating characteristic analysis in this study showed an FG $>87.5 \mathrm{mg} / \mathrm{dL}$ to correspond to a 2-hour glucose from OGTT of $>140 \mathrm{mg} / \mathrm{dL}$. Of note, in these studies, some authors used the previous American Diabetes Association criteria of FG $>110 \mathrm{mg} / \mathrm{dL}$, and some used an FG $>99 \mathrm{mg} / \mathrm{dL}$ to define abnormal FG. In our opinion, using a lower cut-off value of FG of $89 \mathrm{mg} / \mathrm{dL}$ in this particular population of women could potentially increase the sensitivity of the method. More studies are needed to investigate whether using an FG $>89 \mathrm{mg} / \mathrm{dL}$ could be an alternate approach for screening women with PCOS.

Regarding the use of $\mathrm{HbAlc}$, studies have shown conflicting results. Hurd et al showed that HbA1c had only fair agreement with OGTT in diagnosing IGT or diabetes among 111 PCOS women. HbA1c classified two women as IGT who were identified as having diabetes by OGTT. In addition, HbA1c classified 44\% (12/27) of women as normal who had prediabetes according to OGTT. On the contrary, although not 
very sensitive, fasting plasma glucose had substantial agreement with OGTT when compared to HbA1c. ${ }^{52}$ A second large study in 208 women with PCOS was done in Denmark. In this study, the sensitivity and specificity of a $\mathrm{HbAlc}$ value of $6.5 \%$ for the diagnosis of diabetes were $35 \%$ and $99 \%$, respectively, when the 2-hour glucose determination by OGTT was used as a gold standard for diagnosis. The authors found a closer correlation of $\mathrm{HbA} 1 \mathrm{c}$ with waist-to-hip ratio, BMI, and lipid profile than the 2-hour glucose, suggesting the use of HbA1c as a cardiovascular risk marker rather than a glucose intolerance marker, ${ }^{56}$ which is expected given that a high $\mathrm{HbA} 1 \mathrm{c}$ of $6.5 \%$ is diagnostic of diabetes, a known risk factor for cardiovascular disease. In a study done in Korea, HbA1c from 154 patients with PCOS was compared with HbA1c of healthy controls of similar age. Women were divided into groups according to their BMI. HbA1c in obese women with PCOS was similar to obese controls. In lean PCOS women, with a BMI $<25 \mathrm{~kg} / \mathrm{m}^{2}, \mathrm{HbA} 1 \mathrm{c} \geq 5.7 \%$ was significantly higher in PCOS patients when compared to lean control women. The authors suggested using $\mathrm{HbA} 1 \mathrm{c}$ as a screening method for lean PCOS women. Unfortunately, this study was not designed to have 2-hour glucose determined from OGTT. ${ }^{57}$ A small study done several years ago, using as an upper limit of normal $\mathrm{HbAlc}$ a cut-off value of $7.2 \%$, failed to detect IGT in 27 women with PCOS. ${ }^{58}$ More recently, another large study among 671 women with PCOS showed that the use of $\mathrm{HbAlc}$ and fasting plasma glucose cannot be recommended as a screening tool for prediabetes among women with PCOS. ${ }^{59}$

In summary, more studies are needed to evaluate the utility of $\mathrm{HbA} 1 \mathrm{c}$ as a screening tool for prediabetes in women with PCOS.

\section{Glucose intolerance in lean PCOS women}

In 2007, the Androgen Excess Society recommended that all women with PCOS should be screened with an OGTT for glucose intolerance, and the Endocrine Society 2013 guidelines also support this. ${ }^{1}$ However, some studies have supported the idea that lean PCOS women have a lower risk of glucose intolerance.

The glucose intolerance was studied by OGTT among 254 women with PCOS in a clinical study. The prevalence of IGT was 5\% (3/57) and diabetes was 1.8\% (1/57) among PCOS women with a BMI $<25 \mathrm{~kg} / \mathrm{m}^{2}$. Among women with a BMI between 25 and $30 \mathrm{~kg} / \mathrm{m}^{2}$, the prevalence of abnormal results increased significantly to $43 \%(13 / 31){ }^{5,8}$

In a Korean study of 194 women with PCOS, the prevalence of abnormal glucose profile was $5.9 \%$ among lean
PCOS women, versus $30 \%$ and $36.4 \%$ among overweight and obese PCOS women, respectively. The prevalence of glucose intolerance in both lean and obese women with PCOS remained higher compared to age-matched Korean women. $^{20}$

In a cohort of 78 women with PCOS, only one of the 31 women $(3 \%)$ with a BMI $<25 \mathrm{~kg} / \mathrm{m}^{2}$ showed glucose intolerance in the OGTT. BMI was highly predictive of glucose intolerance among women with PCOS. ${ }^{60}$ Between a relatively lean PCOS group of 356 Chinese women (60\% had a BMI $<24 \mathrm{~kg} / \mathrm{m}^{2}$ ), 7.6\% had IGT, and 3.1\% had diabetes. ${ }^{19}$ Studies in Europe have shown a much lower rate of IGT in lean PCOS women. ${ }^{61}$ In a study on 110 native Italian women with PCOS, $15 \%$ showed glucose abnormalities in OGTT, which were evident only in PCOS women who were obese $\left(\mathrm{BMI}>25 \mathrm{~kg} / \mathrm{m}^{2}\right) .{ }^{61}$ The overweight population with PCOS (BMI 25-30 kg/m²) has a significant increase in the risk of glucose intolerance. ${ }^{5,11,19}$

In summary, there is evidence of IGT in lean PCOS women compared to healthy women, but the prevalence of IGT and diabetes is lower when compared to obese PCOS women.

\section{Conclusion}

Women with PCOS are at a higher risk of developing glucose intolerance and diabetes than women in the general population. This seems to be driven by intrinsic insulin receptor defects and post-receptor defects that lead to hyperinsulinemia. Chronic hyperinsulinemia leads to betacell fatigue and increased risk of prediabetes and diabetes. Moreover, women with PCOS can have additional risk factors that are associated with a higher risk of IGT and diabetes. These factors include obesity, the use of OCs, older age, family history of diabetes, and highly irregular menses. Intervention with lifestyle modification, weight loss, exercise, and use of metformin ameliorates the hyperinsulinemia of PCOS. OCs improve the hyperandrogenism by decreasing ovarian steroidogenesis and also by increasing sex hormone-binding globulin and therefore decreasing the bioactive androgens. In the majority of women with PCOS, determination of FG alone might not be sufficient to diagnose glucose intolerance. HbA1c might be beneficial, but more studies are needed to validate its efficacy. All women with PCOS should be screened with an OGTT for glucose intolerance as recommended by the Endocrine Society 2013 guidelines. Larger studies are needed to assess the natural history of glucose intolerance in women with PCOS, when is the appropriate age to start screening for women with PCOS, how often should physicians repeat the OGTT, as well as the factors 
that could alter the conversion rates from normoglycemia to IGT and diabetes in women with PCOS.

\section{Disclosure}

The authors report no conflicts of interest in this work.

\section{References}

1. Legro RS, Arslanian SA, Ehrmann DA, et al. Diagnosis and treatment of polycystic ovary syndrome: an Endocrine Society clinical practice guideline. J Clin Endocrinol Metab. 2013;98(12):4565-4592.

2. Rotterdam ESHRE/ASRM-Sponsored PCOS Consensus Workshop Group. Revised 2003 consensus on diagnostic criteria and long-term health risks related to polycystic ovary syndrome. Fertil Steril. 2004; 81(1):19-25.

3. Diamanti-Kandarakis E, Dunaif A. Insulin resistance and the polycystic ovary syndrome revisited: an update on mechanisms and implications. Endocr Rev. 2012;33(6):981-1030.

4. Lim SS, Davies MJ, Norman RJ, Moran LJ. Overweight, obesity and central obesity in women with polycystic ovary syndrome: a systematic review and meta-analysis. Hum Reprod Update. 2012;18(6): 618-637.

5. Legro RS. Obesity and PCOS: implications for diagnosis and treatment. Semin Reprod Med. 2012;30(6):496-506.

6. Yildiz BO, Knochenhauer ES, Azziz R. Impact of obesity on the risk for polycystic ovary syndrome. J Clin Endocrinol Metab. 2008;93(1): $162-168$.

7. Liang SJ, Hsu CS, Tzeng CR, Chen CH, Hsu MI. Clinical and biochemical presentation of polycystic ovary syndrome in women between the ages of 20 and 40. Hum Reprod. 2011;26(12):3443-3449.

8. Legro RS, Kunselman AR, Dodson WC, Dunaif A. Prevalence and predictors of risk for type 2 diabetes mellitus and impaired glucose tolerance in polycystic ovary syndrome: a prospective, controlled study in 254 affected women. J Clin Endocrinol Metab. 1999;84(1):165-169.

9. Luque-Ramirez M, Alpanes M, Escobar-Morreale HF. The determinants of insulin sensitivity, beta-cell function, and glucose tolerance are different in patients with polycystic ovary syndrome than in women who do not have hyperandrogenism. Fertil Steril. 2010;94(6): 2214-2221.

10. Mani H, Levy MJ, Davies MJ, et al. Diabetes and cardiovascular events in women with polycystic ovary syndrome: a 20-year retrospective cohort study. Clin Endocrinol (Oxf). 2013;78(6):926-934.

11. Norman RJ, Masters L, Milner CR, Wang JX, Davies MJ. Relative risk of conversion from normoglycaemia to impaired glucose tolerance or non-insulin dependent diabetes mellitus in polycystic ovarian syndrome. Hum Reprod. 2001;16(9):1995-1998.

12. Legro RS, Gnatuk CL, Kunselman AR, Dunaif A. Changes in glucose tolerance over time in women with polycystic ovary syndrome: a controlled study. J Clin Endocrinol Metab. 2005;90(6):3236-3242.

13. Boudreaux MY, Talbott EO, Kip KE, Brooks MM, Witchel SF. Risk of T2DM and impaired fasting glucose among PCOS subjects: results of an 8-year follow-up. Curr Diab Rep. 2006;6(1):77-83.

14. Dunaif A, Segal KR, Futterweit W, Dobrjansky A. Profound peripheral insulin resistance, independent of obesity, in polycystic ovary syndrome. Diabetes. 1989;38(9):1165-1174.

15. Ehrmann DA. Polycystic ovary syndrome. NEngl J Med. 2005;352(12): $1223-1236$.

16. Godoy-Matos AF, Vaisman F, Pedrosa AP, Farias MLF, Mendonca LMC, Pinheiro MFMC. Central-to-peripheral fat ratio, but not peripheral body fat, is related to insulin resistance and androgen markers in polycystic ovary syndrome. Gynecol Endocrinol. 2009;25(12):793-798.

17. Yildirim B, Sabir N, Kaleli B. Relation of intra-abdominal fat distribution to metabolic disorders in nonobese patients with polycystic ovary syndrome. Fertil Steril. 2003;79(6):1358-1364.
18. Huang ZH, Manickam B, Ryvkin V, et al. PCOS is associated with increased $\mathrm{CD} 11 \mathrm{c}$ expression and crown-like structures in adipose tissue and increased central abdominal fat depots independent of obesity. J Clin Endocrinol Metab. 2013;98(1):E17-E24.

19. Wei HJ, Young R, Kuo IL, Liaw CM, Chiang HS, Yeh CY. Prevalence of insulin resistance and determination of risk factors for glucose intolerance in polycystic ovary syndrome: a cross-sectional study of Chinese infertility patients. Fertil Steril. 2009;91(5):1864-1868.

20. Lee H, Oh JY, Sung YA, Chung H, Cho WY. The prevalence and risk factors for glucose intolerance in young Korean women with polycystic ovary syndrome. Endocrine. 2009;36(2):326-332.

21. Diamanti-Kandarakis E, Baillargeon JP, Iuorno MJ, Jakubowicz DJ, Nestler JE. A modern medical quandary: polycystic ovary syndrome, insulin resistance, and oral contraceptive pills. J Clin Endocrinol Metab. 2003;88(5):1927-1932.

22. De Pirro R, Forte F, Bertoli A, Greco AV, Lauro R. Changes in insulin receptors during oral contraception. J Clin Endocrinol Metab. 1981;52(1):29-33.

23. Watanabe RM, Azen CG, Roy S, Perlman JA, Bergman RN. Defects in carbohydrate metabolism in oral contraceptive users without apparent metabolic risk factors. J Clin Endocrinol Metab. 1994;79(5): $1277-1283$.

24. Godsland IF, Crook D, Simpson R, et al. The effects of different formulations of oral contraceptive agents on lipid and carbohydrate metabolism. N Engl J Med. 1990;323(20):1375-1381.

25. Meyer C, McGrath BP, Teede HJ. Effects of medical therapy on insulin resistance and the cardiovascular system in polycystic ovary syndrome. Diabetes Care. 2007;30(3):471-478.

26. Morin-Papunen LC, Vauhkonen I, Koivunen RM, Ruokonen A, Martikainen HK, Tapanainen JS. Endocrine and metabolic effects of metformin versus ethinyl estradiol-cyproterone acetate in obese women with polycystic ovary syndrome: a randomized study. JClin Endocrinol Metab. 2000;85(9):3161-3168.

27. Morin-Papunen L, Vauhkonen I, Koivunen R, Ruokonen A, Martikainen H, Tapanainen JS. Metformin versus ethinyl estradiol-cyproterone acetate in the treatment of nonobese women with polycystic ovary syndrome: a randomized study. J Clin Endocrinol Metab. 2003;88(1): 148-156.

28. Orio F, Muscogiuri G, Giallauria F, et al. Oral contraceptives versus physical exercise on cardiovascular and metabolic risk factors in women with polycystic ovary syndrome: a randomized controlled trial. Clin Endocrinol (Oxf). Epub 2016 May 24.

29. Adeniji AA, Essah PA, Nestler JE, Cheang KI. Metabolic effects of a commonly used combined hormonal oral contraceptive in women with and without polycystic ovary syndrome. $J$ Womens Health (Larchmt). 2016;25(6):638-645.

30. Yildiz BO. Approach to the patient: contraception in women with polycystic ovary syndrome. J Clin Endocrinol Metab. 2015;100(3): 794-802.

31. Ehrmann DA, Kasza K, Azziz R, Legro RS, Ghazzi MN. Effects of race and family history of type 2 diabetes on metabolic status of women with polycystic ovary syndrome. J Clin Endocrinol Metab. 2005; 90(1):66-71.

32. Gambineri A, Pelusi C, Manicardi E, et al. Glucose intolerance in a large cohort of mediterranean women with polycystic ovary syndrome: phenotype and associated factors. Diabetes. 2004;53(9):2353-2358.

33. Ehrmann DA, Barnes RB, Rosenfield RL, Cavaghan MK, Imperial J. Prevalence of impaired glucose tolerance and diabetes in women with polycystic ovary syndrome. Diabetes Care. 1999;22(1):141-146.

34. Solomon CG, Hu FB, Dunaif A, et al. Long or highly irregular menstrual cycles as a marker for risk of type 2 diabetes mellitus. JAMA. 2001;286(19):2421-2426.

35. Gast G-CM, Grobbee DE, Smit HA, Bueno-de-Mesquita HB, Samsioe GN, van der Schouw YT. Menstrual cycle characteristics and risk of coronary heart disease and type 2 diabetes. Fertil Steril. 2010; 94(6):2379-2381. 
36. Brower M, Brennan K, Pall M, Azziz R. The severity of menstrual dysfunction as a predictor of insulin resistance in PCOS. J Clin Endocrinol Metab. 2013;98(12):E1967-E1971.

37. Ehrmann DA, Sturis J, Byrne MM, Karrison T, Rosenfield RL, Polonsky KS. Insulin secretory defects in polycystic ovary syndrome. Relationship to insulin sensitivity and family history of non-insulindependent diabetes mellitus. J Clin Invest. 1995;96(1):520-527.

38. Dunaif A, Finegood DT. Beta-cell dysfunction independent of obesity and glucose intolerance in the polycystic ovary syndrome. J Clin Endocrinol Metab. 1996;81(3):942-947.

39. Arslanian SA, Lewy VD, Danadian K. Glucose intolerance in obese adolescents with polycystic ovary syndrome: roles of insulin resistance and beta-cell dysfunction and risk of cardiovascular disease. $J$ Clin Endocrinol Metab. 2001;86(1):66-71.

40. Glintborg D, Hojlund K, Andersen NR, Hansen BF, Beck-Nielsen H, Wojtaszewski JFP. Impaired insulin activation and dephosphorylation of glycogen synthase in skeletal muscle of women with polycystic ovary syndrome is reversed by pioglitazone treatment. J Clin Endocrinol Metab. 2008;93(9):3618-3626.

41. Pierce GL, Zhu H, Darracott K, et al. Arterial stiffness and pulsepressure amplification in overweight/obese African-American adolescents: relation with higher systolic and pulse pressure. Am J Hypertens. 2013;26(1):20-26.

42. Manneras-Holm L, Leonhardt H, Kullberg J, et al. Adipose tissue has aberrant morphology and function in PCOS: enlarged adipocytes and low serum adiponectin, but not circulating sex steroids, are strongly associated with insulin resistance. J Clin Endocrinol Metab. 2011; 96(2):E304-E311.

43. Sarray S, Madan S, Saleh LR, Mahmoud N, Almawi WY. Validity of adiponectin-to-leptin and adiponectin-to-resistin ratios as predictors of polycystic ovary syndrome. Fertil Steril. 2015;104(2):460-466.

44. Repaci A, Gambineri A, Pasquali R. The role of low-grade inflammation in the polycystic ovary syndrome. Mol Cell Endocrinol. 2011; 335(1):30-41.

45. Luotola K, Piltonen TT, Puurunen J, Tapanainen JS. IL-1 receptor antagonist levels are associated with glucose tolerance in polycystic ovary syndrome. Clin Endocrinol (Oxf). Epub 2016 Apr 7.

46. Diamanti-Kandarakis E, Paterakis T, Alexandraki K, et al. Indices of low-grade chronic inflammation in polycystic ovary syndrome and the beneficial effect of metformin. Hum Reprod. 2006;21(6):1426-1431.

47. Kim JJ, Choi YM. Dyslipidemia in women with polycystic ovary syndrome. Obstet Gynecol Sci. 2013;56(3):137-142.

48. Roe A, Hillman J, Butts S, et al. Decreased cholesterol efflux capacity and atherogenic lipid profile in young women with PCOS. J Clin Endocrinol Metab. 2014;99(5):E841-E847.

49. Gourgari E, Lodish M, Shamburek R, et al. Lipoprotein particles in adolescents and young women with PCOS provide insights into their cardiovascular risk. J Clin Endocrinol Metab. 2015;100(11):4291-4298.
50. Lorenzi GM, Braffett BH, Arends VL, et al. Quality control measures over 30 years in a multicenter clinical study: results from the Diabetes Control and Complications Trial/Epidemiology of Diabetes Interventions and Complications (DCCT/EDIC) study. PLoS One. 2015;10(11): e0141286.

51. Salley KES, Wickham EP, Cheang KI, Essah PA, Karjane NW, Nestler JE. Glucose intolerance in polycystic ovary syndrome - a position statement of the Androgen Excess Society. J Clin Endocrinol Metab. 2007;92(12):4546-4556.

52. Hurd WW, Abdel-Rahman MY, Ismail SA, Abdellah MA, Schmotzer CL, Sood A. Comparison of diabetes mellitus and insulin resistance screening methods for women with polycystic ovary syndrome. Fertil Steril. 2011;96(4):1043-1047.

53. Vrbikova J, Dvorakova K, Grimmichova T, et al. Prevalence of insulin resistance and prediction of glucose intolerance and type 2 diabetes mellitus in women with polycystic ovary syndrome. Clin Chem Lab Med. 2007;45(5):639-644.

54. Barcellos CR, Rocha MP, Hayashida SA, Nery M, Marcondes JA. Prevalence of abnormalities of glucose metabolism in patients with polycystic ovary syndrome. Arq Bras Endocrinol Metabol. 2007;51(4): 601-605.

55. Palmert MR, Gordon CM, Kartashov AI, Legro RS, Emans SJ, Dunaif A Screening for abnormal glucose tolerance in adolescents with polycystic ovary syndrome. J Clin Endocrinol Metab. 2002;87(3):1017-1023.

56. Velling Magnussen L, Mumm H, Andersen M, Glintborg D. Hemoglobin A1c as a tool for the diagnosis of type 2 diabetes in 208 premenopausal women with polycystic ovary syndrome. Fertil Steril. 2011; 96(5):1275-1280.

57. Kim JJ, Choi YM, Cho YM, et al. Prevalence of elevated glycated hemoglobin in women with polycystic ovary syndrome. Hum Reprod. 2012;27(5):1439-1444.

58. Golland IM, Vaughan Williams CA, Shalet SM, Million LH, Elstein M Lack of predictive value of $\mathrm{HbA} 1$ for impaired glucose tolerance in polycystic ovary syndrome. Gynecol Endocrinol. 1989;3(3):229-235.

59. Lerchbaum E, Schwetz V, Giuliani A, Obermayer-Pietsch B. Assessment of glucose metabolism in polycystic ovary syndrome: HbA1c or fasting glucose compared with the oral glucose tolerance test as a screening method. Hum Reprod. 2013;28(9):2537-2544.

60. Stovall DW, Bailey AP, Pastore LM. Assessment of insulin resistance and impaired glucose tolerance in lean women with polycystic ovary syndrome. J Womens Health (Larchmt). 2011;20(1):37-43.

61. Ciampelli M, Fulghesu AM, Cucinelli F, et al. Impact of insulin and body mass index on metabolic and endocrine variables in polycystic ovary syndrome. Metabolism. 1999;48(2):167-172.
International Journal of Women's Health

\section{Publish your work in this journal}

The International Journal of Women's Health is an international, peerreviewed open-access journal publishing original research, reports, editorials, reviews and commentaries on all aspects of women's healthcare including gynecology, obstetrics, and breast cancer. The manuscript management system is completely online and includes

\section{Dovepress}

a very quick and fair peer-review system, which is all easy to use. Visit http://www.dovepress.com/testimonials.php to read real quotes from published authors. 